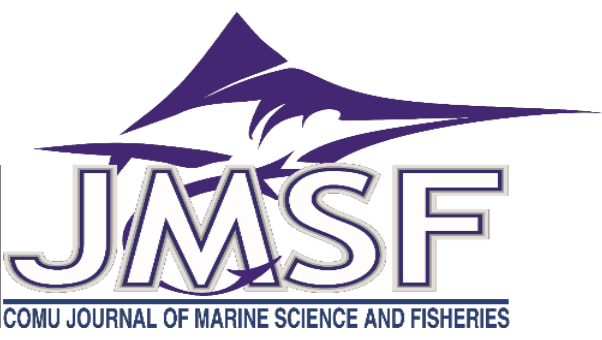

REVIEW

\title{
Fishing and Aquaculture in the Provinces of Konya Plain Project Regional Development Administration
}

\author{
Erdoğan Çiçek ${ }^{1 *}$, Sevil Sungur ${ }^{2}$, Mustafa Öz ${ }^{3}$ \\ ${ }^{1}$ Nevşehir Hacı Bektaş Veli Üniversitesi, Fen Edebiyat Fakültesi, Biyoloji Bölümü, 50300 Nevşehir/Türkiye \\ ${ }^{2}$ Nevşehir Hacı Bektaş Veli Üniversitesi, Sağlık Hizmetleri MYO, 50300 Nevşehir/Türkiye \\ ${ }^{3}$ Aksaray Üniversitesi, Veteriner Fakültesi, Aksaray/Türkiye \\ Correspondent: erdogancicek@nevsehir.edu.tr \\ Received: 01.05.2020 Accepted: 15.06.2020 \\ Erdoğan Çiçek: Orcid 0000-0002-5334-5737, Sevil Sungur: Orcid 0000-0003-4018-6375, Mustafa Öz: Orcid 0000-0001-5264-7103
}

How to cite this article: Ciçek, E., Sungur, S., \& Öz, M., (2020). Fishing and aquaculture in the provinces of Konya Plain Project Regional Development Administration. COMU J. Mar. Sci. Fish, 3(1): 51-56. DOI: 10.46384/jmsf.730371

Abstract: In the provinces covered by Konya Plain Project (KOP) Regional Development Administration, fishing and aquaculture statistics were examined and the current situation was revealed. Approximately, 1.12\% of Turkey's total aquaculture production is carried out in KOP. Rainbow trout $(98.5 \%)$ is the most commonly cultivated species in the region and tilapia $(0.9 \%)$ and carp $(0.6 \%)$ are grown in small amounts. No aquaculture is carried out in Kirikkale and Aksaray provinces, and the highest production is in Kirsehir (35.2\%), Yozgat $(24.5 \%)$ and Karaman (24.3\%), respectively. In 2018, a total of 3.259 tons captured in KOP, corresponding to $10.8 \%$ of total fishing catch in Turkey. During 2016-2018, the highest mean yields from fishing was realized in Yozgat $(36.5 \%)$ followed by Kirsehir $(30.0 \%)$ and Konya (23.6\%). With regard to species composition, bigscale sand smelt had the highest catch rate with $37.5 \%$ and followed by gibel carp (36.5\%), common carp (12.8\%), zander (5.8\%) and crayfish $(2.4 \%)$, respectively. The catch rate of all other species was around $1.0 \%$ or less. In order to increase the amount of yields from fisheries in the KOP region, strategies should be developed in line with the principles of sustainable fishing and aquaculture-based production should be promoted in suitable areas.

Keywords: Konya, Karaman, Nevsehir, Nigde, Aksaray, Kirsehir, Kirikkale, Yozgat

\section{Konya Ovası Projesi Bölge Kalkınma İdaresi İllerinde Su Ürünleri Avcılığı ve Yetiştiriciliği}

Özet: Konya Ovası Projesi (KOP) Bölge Kalkınma İdaresi kapsamındaki illerde su ürünleri avcılık ve yetiştiricilik istatistikleri incelenerek mevcut durum ortaya konmuştur. KOP Bölgesinde Türkiye'nin toplam su ürünleri üretiminin \%1,12'lik kısmı gerçekleştirilmektedir. Bölgede en fazla yetiştiriciliği yapılan tür gökkuşağ 1 alabalığ $1(\% 98,5)$ olup çok az miktarlarda tilapya $(\% 0,9)$ ve sazan $(\% 0,6)$ yetiștirilmektedir. Kırıkkale ve Aksaray illerinde hiçbir su ürünleri yetiştiriciliği yapılmamakta iken en fazla yetiştiricilik Kırşehir $(\% 35,2)$, Yozgat $(\% 24,5)$ ve Karaman $(\% 24,3)$ illerinde gerçekleştirilmektedir. KOP Bölgesinde 2018 yılı itibariyle 3.259 ton su ürünleri avcılığı yapılmış olup bu değer Türkiye'nin toplam su ürünleri avcılığının \%10,8'ine tekabül etmektedir. 2016-2018 yılları ortalamasına göre en yüksek avcıllk Yozgat $(\% 36,5)$ İlinde gerçekleştirilmiş olup bunu Kırşehir $(\% 30,0)$ ve Konya $(\% 23,6)$ illeri izlemektedir. Tür bazında ise en yüksek avc1lık değerine sahip tür $\% 37,5$ 'lik oran ile gümüş balığ 1 olup bunu sırasıyla gümüşi havuz balığ $(\% 36,5)$, sazan $(\% 12,8)$, sudak $(\% 5,8)$ ve kerevit $(\% 2,4)$ izlemektedir. Diğer türler ise $\% 1,0$ civarında veya daha düşük oranlarda avlanmaktadır. KOP Bölgesinde avcılıktan elde edilen ürün miktarının arttırılmasına yönelik olarak sürdürülebilir avcılık ilkeleri doğrultusunda stratejiler geliştirilmesi ve uygun alanlarda yetiştiriciliğin desteklenmesi gerekmektedir.

Anahtar Kelimeler: Konya, Karaman, Nevşehir, Niğde, Aksaray, Kırşehir, Kırıkkale, Yozgat 


\section{Giriş}

Başta balıklar olmak üzere su ürünleri insan beslenmesinde çok önemli bir kaynak olarak değerlendirilmektedir. Hatay Mozaik Müzesinde yer alan mozaiklerde bazı deniz balıkları ve kabuklular figüre edilmiştir. Benzer şekilde Zeugma Antik Kentinden çıkartılan mozaiklerde de bazı tatlı su balıklarına (Arabibarbus grypus) yer verilmiştir. Bu durum eski dönemlerden beri su ürünlerinin kullanımının önemini ortaya koymaktadır.

Doğadan avcılık ve toplayıcılık ile başlayan su ürünleri elde edilmesinde gerek doğal kaynakların azalması ve gerekse doğal stokların ihtiyacını karşılamaktan uzak olması gibi nedenlerden dolayı bazı türlerin yetiştiriciliğine başlanmıştır. Günümüzde tüm dünyada yetiştiricilik yoluyla üretilen ürün miktarı yıldan yıla artış göstererek neredeyse avcılık yoluyla elde edilen ürün miktarına yaklaşmış durumdadır (Anonim, 2019).

$\mathrm{Su}$ ürünleri uluslararası alanda en çok ticareti yapılan gida maddelerinin başında gelmektedir (Özdemir ve Aras, 2005). Yılda 60 milyon tonun üzerinde su ürünü ticareti yapılmakta olup değer dünya üretiminin yaklaşı \%40'ına karşıllk gelmektedir. Oluşturulan ticaret hacmi ise 150 milyar doları aşmış durumdadır (FAO, 2019). Bazı ülkelerin su ürünleri üretimi ve ticaretiyle milli gelirlerine kattıkları maddi değerlerin oldukça büyük rakamlara ulaştığı görülmektedir. Ulaşım, depolama, pazarlama olanaklarının hızlanması ve gelişmesi denizlerden uzak kesimlerde bulunanların da bu ürünlerden yararlanabilmelerini, dolayısıyla bu tür besin maddelerinin insanların tüketimlerindeki yer ve paylarını da giderek arttırmaktadır (Emiroğlu, 1987).

$\mathrm{Su}$ ürünleri ticaretine ilişkin olarak 195 ülke ihracat yaparken 199 ülke ise ithalat yapmaktadır. Gelişmiş ülkeler su ürünleri ithalatının $\% 85^{\prime}$ 'ini gerçekleştirirken, toplam ithalatın \%25'i Japonya tarafindan yapılmaktadır. AB ise balık ihtiyacını karşılamada dışa bağımlılığı arttırmıştır ve değerce dünya ithalatından aldığı pay \%35 olmuştur (Anonim, 2005).

Bu çalışma ile Konya Ovası Projesi (KOP) Bölge Kalkınma İdaresi illerinde su ürünleri avcılığı ve yetiştiriciliğinin durumunun ortaya konması amaçlanmıştır. Bunun yanı sıra durum değerlendirmesi yapılarak sektörün sorunlarına dikkat çekilmesi ve sektörün gelişmesine yönelik çözüm önerilerinin tartışılması amaçlanmıştır.

\section{Materyal ve Yöntem}

KOP Bölgesi illerindeki su ürünleri avcılığı ve yetiştiriciliğinin durumunun ortaya konması amaciyla Türkiye İstatistik Kurumu (TUİK) ve Dünya Tarım ve Gıda Örgütü (FAO) tarafından yayınlanmış su ürünleri istatistikleri kullanılmıştır (FAO, 2019; TÜİK, 2019). Ayrıca bölge illerinde yapılan arazi çalışmalarındaki gözlemlere de yer verilmiştir.

\section{Bulgular}

Dünyada doğal balık stokları maksimum düzeyde sömürülmekte olup son 10 y1llık dönemde ortalama 89.895 ( \pm 1.605$)$ milyon ton ile maksimum seviyeye çıkmış durumdadır (Tablo 1) (FAO, 2019). Buna karşın 2008 yılında 142,4 milyon ton olan toplam su ürünleri üretimi ise, 2017 yılında 172,6 milyon tona yükselmiştir. Son 10 yılda meydana gelen \%20'lik bu artış yetiştiriciliğin toplam üretimdeki payının yıldan yıla artmasından kaynaklanmaktadır. Nitekim 2008 y1lında \%37,16 olan oran 2017 y1linda \%46,42'ye yükselmiş durumdadır.

1997 yılında dünyada ülkeler arası ticarete konu olan su ürünleri miktarı 45 milyon tonken, 2007 yılında 52 milyon tona ve 2017 yılında ise 65 milyon tona yükselmiş durumdadır. $\mathrm{Bu}$ artışın çok daha ötesinde parasal anlamdaki ticaret hacmi ise 1997 yılında 53 milyar dolardan 2007 yılında 94 milyar dolar ve 2017 yılında ise 156 milyar dolara yükselmiştir (FAO, 2019).

Tablo 1. Dünyanın su ürünleri üretiminin son 10 yıllık durumu (x1000 ton) (FAO, 2019)

\begin{tabular}{|c|c|c|c|c|c|c|}
\hline \multirow{2}{*}{ Yll } & \multicolumn{2}{|c|}{ Avcılık } & \multicolumn{2}{|c|}{ Yetiştiricilik } & \multirow{2}{*}{$\begin{array}{l}\text { Toplam } \\
\text { Miktar } \\
\end{array}$} & \multirow{2}{*}{$\begin{array}{l}\text { Ticareti } \\
\text { Yapılan } \\
\text { Miktar } \\
\end{array}$} \\
\hline & Miktar & $\%$ & Miktar & $\%$ & & \\
\hline 2008 & 89.484 & 62,84 & 52.914 & 37,16 & 142.398 & 54.403 \\
\hline 2009 & 89.050 & 61,75 & 55.156 & 38,25 & 144.206 & 54.992 \\
\hline 2010 & 87.133 & 60,14 & 57.743 & 39,86 & 144.876 & 54.606 \\
\hline 2011 & 91.520 & 60,48 & 59.791 & 39,52 & 151.311 & 57.270 \\
\hline 2012 & 88.448 & 58,22 & 63.476 & 41,78 & 151.924 & 60.046 \\
\hline 2013 & 89.624 & 57,24 & 66.949 & 42,76 & 156.573 & 59.165 \\
\hline 2014 & 90.230 & 56,14 & 70.501 & 43,86 & 160.731 & 61.804 \\
\hline 2015 & 91.541 & 55,71 & 72.772 & 44,29 & 164.313 & 59.177 \\
\hline 2016 & 89.419 & 53,92 & 76.425 & 46,08 & 165.844 & 59.542 \\
\hline 2017 & 92.509 & 53,58 & 80.133 & 46,42 & 172.642 & 64.876 \\
\hline
\end{tabular}


Türkiye'de 2000 yılından itibaren su ürünleri üretimine bakıldığında ortalama yıllık toplam su ürünleri üretim miktarının $629.117( \pm 55.878)$ ton olarak gerçekleştiği görülmektedir (TÜİK, 2019). Yıllar itibariyle toplam ürün miktarında fazla bir değişiklik söz konusu değilken, toplam üretim içerisindeki yetiştiriciliğin payı yıldan yıla artış göstererek \%10'lardan dünyada olduğu gibi \%50 seviyesine yükselmiş durumdadır. Ülkemizdeki yetiştiricilik faaliyetleri dünya ülkelerine göre çok daha geç bir dönemde başlamış olmasına karşın son yıllarda çok büyük bir sıçrama gerçekleştirmiş durumdadir.

Tablo 2. Türkiye'de toplam su ürünleri üretiminin yıllık değişimi (TÜİK, 2019)

\begin{tabular}{|c|c|c|c|c|c|}
\hline \multirow{2}{*}{ Yll } & \multicolumn{2}{|c|}{ Avcılk } & \multicolumn{2}{c|}{ Yetiştiricilik } & Toplam \\
\cline { 2 - 6 } & Miktar (ton) & \% & Miktar (ton) & Miktar (ton) \\
\hline 2000 & 503.345 & 86,4 & 79.031 & 13,6 & 582.376 \\
\hline 2001 & 527.733 & 88,7 & 67.244 & 11,3 & 594.977 \\
\hline 2002 & 566.682 & 90,3 & 61.165 & 9,7 & 627.847 \\
\hline 2003 & 507.772 & 86,4 & 79.943 & 13,6 & 587.715 \\
\hline 2004 & 550.482 & 85,4 & 94.010 & 14,6 & 644.492 \\
\hline 2005 & 426.496 & 78,3 & 118.277 & 21,7 & 544.773 \\
\hline 2006 & 533.048 & 80,5 & 128.943 & 19,5 & 661.991 \\
\hline 2007 & 632.450 & 81,9 & 139.873 & 18,1 & 772.323 \\
\hline 2008 & 494.124 & 76,5 & 152.186 & 23,5 & 646.310 \\
\hline 2009 & 464.462 & 74,5 & 158.729 & 25,5 & 623.191 \\
\hline 2010 & 485.939 & 74,4 & 167.141 & 25,6 & 653.080 \\
\hline 2011 & 514.755 & 73,2 & 188.790 & 26,8 & 703.545 \\
\hline 2012 & 432.442 & 67,1 & 212.410 & 32,9 & 644.852 \\
\hline 2013 & 374.121 & 61,6 & 233.394 & 38,4 & 607.515 \\
\hline 2014 & 302.212 & 56,2 & 235.133 & 43,8 & 537.345 \\
\hline 2015 & 431.907 & 64,2 & 240.334 & 35,8 & 672.241 \\
\hline 2016 & 335.320 & 57,0 & 253.395 & 43,0 & 588.715 \\
\hline 2017 & 354.318 & 56,2 & 276.502 & 43,8 & 630.820 \\
\hline 2018 & 314.094 & 50,0 & 314.537 & 50,0 & 628.631 \\
\hline
\end{tabular}

Türkiye'de doğal stokların sömürülmesi sonucu avcılık yoluyla elde edilen ürün miktarı 2000'li y1llarda ortalama 500 bin ton/yıl düzeyindeyken son yıllarda çok büyük bir düșüş eğilimine girerek 300 bin tonlara gerilemiş durumdadır (Tablo 3). İç sularda avcılık yoluyla elde edilen üretim miktarının payı ise $\% 9$ civarında sabit bir seyir izlemektedir

Tablo 3. Türkiye'de su ürünleri avcılığının yıllık değişimi (TÜİK, 2019)

\begin{tabular}{|l|c|c|c|c|c|}
\hline \multirow{2}{*}{ Yil } & \multicolumn{2}{|c|}{ Deniz } & \multicolumn{2}{c|}{ İ Su } & Toplam \\
\cline { 2 - 6 } & Miktar (ton) & \% & Miktar (ton) & \% & Miktar (ton) \\
\hline 2000 & 460.521 & 91,5 & 42.824 & 8,5 & 503.345 \\
\hline 2001 & 484.410 & 91,8 & 43.323 & 8,2 & 527.733 \\
\hline 2002 & 522.744 & 92,2 & 43.938 & 7,8 & 566.682 \\
\hline 2003 & 463.074 & 91,2 & 44.698 & 8,8 & 507.772 \\
\hline 2005 & 504.897 & 91,7 & 45.585 & 8,3 & 550.482 \\
\hline 2006 & 380.381 & 89,2 & 46.115 & 10,8 & 426.496 \\
\hline 2007 & 488.966 & 91,7 & 44.082 & 8,3 & 533.048 \\
\hline 2008 & 589.129 & 93,2 & 43.321 & 6,8 & 632.450 \\
\hline 2009 & 453.113 & 91,7 & 41.011 & 8,3 & 494.124 \\
\hline 2010 & 425.275 & 91,6 & 39.187 & 8,4 & 464.462 \\
\hline 2011 & 445.680 & 91,7 & 40.259 & 8,3 & 485.939 \\
\hline 2012 & 477.658 & 92,8 & 37.097 & 7,2 & 514.755 \\
\hline 2013 & 396.322 & 91,6 & 36.120 & 8,4 & 432.442 \\
\hline 2014 & 339.047 & 90,6 & 35.074 & 9,4 & 374.121 \\
\hline 2015 & 266.078 & 88,0 & 36.134 & 12,0 & 302.212 \\
\hline 2016 & 397.731 & 92,1 & 34.176 & 7,9 & 431.907 \\
\hline 2017 & 301.464 & 89,9 & 33.856 & 10,1 & 335.320 \\
\hline 2018 & 322.173 & 90,9 & 32.145 & 9,1 & 354.318 \\
\hline
\end{tabular}


Türkiye'de su ürünleri üretimindeki en önemli gelişme 1980 yıllarının ortalarında iç sularda gökkuşağı alabalığı (Oncorhynchus mykiss) ile başlamış olan su ürünleri yetiştiriciliğinde görülmüştür (Tablo 4). 2000 yılında 80 bin ton civarında olan üretim miktarı bugün 300 bin tonlara dayanmış durumdadır. İç sularda yapılan büyük çoğunluğu gökkuşağı alabalığına dayalı olan yetiştiricilik miktarı, 2000 yılında toplam üretimin $\% 55$ 'ini oluştururken, denizlerde yapılan üretim miktarı son yıllarda büyük bir artış göstererek 2017 y1lında \%62,4 olarak gerçekleşmiştir.

Tablo 4. Türkiye'de yetiştiricilik yoluyla üretilen su ürünleri miktarının yıllık değişimi (TÜIK, 2019)

\begin{tabular}{|c|c|c|c|c|c|}
\hline \multirow[t]{2}{*}{ Yıl } & \multicolumn{2}{|l|}{ Deniz } & \multicolumn{2}{|l|}{ İç Sular } & \multirow{2}{*}{$\frac{\text { Toplam }}{\text { Miktar (ton) }}$} \\
\hline & Miktar (ton) & $\%$ & Miktar (ton) & $\%$ & \\
\hline 2000 & 35.646 & 45,1 & 43.385 & 54,9 & 79.031 \\
\hline 2001 & 29.730 & 44,2 & 37.514 & 55,8 & 67.244 \\
\hline 2002 & 26.868 & 43,9 & 34.297 & 56,1 & 61.165 \\
\hline 2003 & 39.726 & 49,7 & 40.217 & 50,3 & 79.943 \\
\hline 2004 & 49.895 & 53,1 & 44.115 & 46,9 & 94.010 \\
\hline 2005 & 69.673 & 58,9 & 48.604 & 41,1 & 118.277 \\
\hline 2006 & 72.249 & 56,0 & 56.694 & 44,0 & 128.943 \\
\hline 2007 & 80.840 & 57,8 & 59.033 & 42,2 & 139.873 \\
\hline 2008 & 85.629 & 56,3 & 66.557 & 43,7 & 152.186 \\
\hline 2009 & 82.481 & 52,0 & 76.248 & 48,0 & 158.729 \\
\hline 2010 & 88.573 & 53,0 & 78.568 & 47,0 & 167.141 \\
\hline 2011 & 88.344 & 46,8 & 100.446 & 53,2 & 188.790 \\
\hline 2012 & 100.853 & 47,5 & 111.557 & 52,5 & 212.410 \\
\hline 2013 & 110.375 & 47,3 & 123.019 & 52,7 & 233.394 \\
\hline 2014 & 126.894 & 54,0 & 108.239 & 46,0 & 235.133 \\
\hline 2015 & 138.879 & 57,8 & 101.455 & 42,2 & 240.334 \\
\hline 2016 & 151.794 & 59,9 & 101.601 & 40,1 & 253.395 \\
\hline 2017 & 172.492 & 62,4 & 104.010 & 37,6 & 276.502 \\
\hline 2018 & 209.370 & 66,6 & 105.167 & 33,4 & 314.537 \\
\hline
\end{tabular}

2018 yılında Türkiye iç sularında avcılığ yapılmış olan 30.139 ton su ürünlerinin 3.259 tonu $(\% 10,8)$ KOP Bölgesi illerinden elde edilmiştir (Tablo 5). İller itibariyle en fazla avcılık Kırşehir'de
(1.208 ton) gerçekleştirilmiş olup bunu Yozgat (1.133 ton) ve Konya (800 ton) izlemektedir. En düşük avcılık miktarı ise 11 ton ile Niğde'de elde edilmiştir.

Tablo 5. KOP Bölgesi İlleri 2018 yılı itibariyle avlanan türler ve avcılık miktarları. *: egzotik türler, +: taşınmış türler (TÜİK, 2019)

\begin{tabular}{|c|c|c|c|c|c|c|c|c|c|c|c|}
\hline Türler & 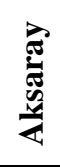 & 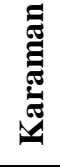 & 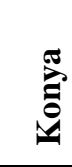 & 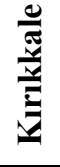 & 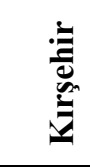 & 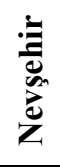 & 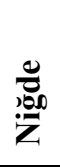 & 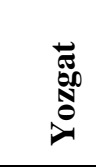 & $\hat{\theta}$ & $b^{0}$ & : \\
\hline Gümüş* & & & & & 670 & & & 664 & 1334 & 28,8 & 4630 \\
\hline Gümüşi Havuz Balığ 1 * & & & 365 & & 425 & & & 320 & 1110 & 18,2 & 6114 \\
\hline Sazan+ & 25 & 25 & 165 & 20 & 50 & 5 & 5 & 80 & 375 & 13,3 & 2816 \\
\hline Sudak+ & 8 & & 208 & & 6 & 1 & & 6 & 229 & 55,6 & 412 \\
\hline Kerevit* & 1 & & 15 & & 35 & & & 1 & 52 & 9,9 & 524 \\
\hline Siraz & & 1 & 2 & & 2 & & & 33 & 38 & 6,1 & 619 \\
\hline Yayın & 3 & 4 & 8 & 1 & 10 & 4 & & 1 & 31 & 9,0 & 344 \\
\hline Kefal & & & 12 & & & & 1 & 10 & 23 & 2,2 & 1056 \\
\hline Kadife+ & 3 & & 4 & & 6 & 2 & 3 & & 18 & 60,0 & 30 \\
\hline Alabalık & & & 4 & & & & & 12 & 16 & 5,7 & 282 \\
\hline Çapak & & & 4 & 1 & & & & & 5 & 6,8 & 74 \\
\hline Kizılkanat & & & & & & 2 & 2 & & 4 & 4,4 & 91 \\
\hline Turna & & & & 1 & & & & & 1 & 0,6 & 181 \\
\hline Diğer & & & 13 & & 4 & & & 6 & 23 & 6,0 & 384 \\
\hline Toplam & 40 & 30 & 800 & 23 & 1208 & 14 & 11 & 1133 & 3259 & 10,8 & 30139 \\
\hline
\end{tabular}


KOP Bölgesi illerinde 12'si balık ve 1 tanesi kabuklu (kerevit) olmak üzere 13 türün avcılığına ilişkin istatistiklere yer verilmektedir. En yüksek avcılık değerine sahip olan tür gümüş balığ (1.334 ton) bunu gümüşi sazan balığı (1.110 ton), sazan (375 ton) ve sudak (229 ton) izlemektedir.

Ancak avlanan türlere bakıldığında tür bazlı istatistiklerde bazı sorunlar olduğu göze çarpmaktadır. Örneğin Kizılkanat (Scardinus erythrophthalmus) türünün Niğde ve Nevşehir illerinde 2'şer ton avcılığının olduğu rapor edilmiştir. Ancak söz konusu tür her iki ilde de doğal olarak dağılım göstermemektedir. $\mathrm{Bu}$ durum istatistik toplanmasında ya da türlerinin yerel isimlerinin kullanılmasında bir sorun olduğuna işaret etmektedir. Bunun yanı sıra bölgede sportif olta balıkçılığı ile avlandığı ve tüketildiği bilinen bazı türlerin istatistiklerde yer almadığı görülmüştür. Örneğin Nevşehir ili istatistiklerinde siraz, tatlı su kefali, barbus vb. gibi türler avlanırken istatistiklerde yer almamaktadır. Su ürünleri istatistiklerinin toplanması ile ilgili İl Tarım ve Orman Müdürlüklerinin bilgilendirilmesinin gerekliliği ortaya çıkmaktadır.

KOP Bölgesi illerinde 3 balık türünün yetiştiriciliği yapılmaktadır. En yüksek üretim değerine sahip tür tüm Türkiye'de olduğu gibi $O$. mykiss (3.197 ton) olup bunu Cyprinus carpio (212 ton) ve Oreochromis sp. (12 ton) izlemektedir. İller itibariyle 2018 yılında en fazla yetiştiricilik
Kırşehir'de (1.107 ton) gerçekleştirilmiş olup bunu Yozgat (1.051 ton) ve Karaman (678) izlemektedir. KOP Bölgesi illerindeki alabalık yetiştiriciliği barajlardaki ağ kafeslere dayalı olarak yapılmaktadır. Az miktardaki bir kısmı ise, Niğde ilinde olduğu gibi, akarsuların kaynak bölgelerine yakın kısımlarda kurulmuş olan alabalık çiftliklerindeki havuzlarda yetiştirilmektedir.

Yetiştiricilik açısından en ilginç durumlardan birisi ise Oreochromis sp. yetiştiriciliğidir. Cichlidae familyasına mensup ve genel olarak tilapya olarak isimlendirilen balık türlerinin yetiştiriciliği hızlı büyümeleri, düşük oksijene sahip kirli sayllabilecek sucul ekosistemlere dayanıklı olmaları, her türlü besinle beslenebilmeleri gibi biyolojik özellikleri nedeniyle ülkemizde Su Ürünleri Fakültelerinde, havuz, ağ kafes ve hatta tuzlu su ortamlarında deneme üretimleri şeklinde yapılmıştır (Dikel, 2001, 2006). Ancak bu türlerin düşük sıcaklıklara karşı toleranssız olmaları, talep görmemeleri ve düşük pazar değerleri nedeniyle yetiştiriciliği yaygınlaşamamıştır. Ülkemizde bu türün yetiștiriciliğinin yapıldığı tek il Konya olup 2018 y1lı itibariyle 12 ton üretim gerçekleştirilmiştir. Söz konusu üretim Konya Şeker Fabrikasının soğutma suyu havuzlarının balık üretimi amacıyla değerlendirilmesi için yapılmaktadır. Nevşehir ve Yozgat illerinde düşük miktarda da olsa C. carpio türü yetiştirilmektedir.

Tablo 6. KOP Bölgesindeki illerde yetiştiriciliği yapılan balık türlerinin 2016-2018 yılları arasındaki üretim miktarları (TÜİK, 2019)

\begin{tabular}{|c|c|c|c|c|c|c|c|c|c|c|}
\hline Türler & $\equiv$ & 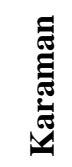 & 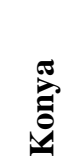 & 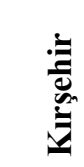 & 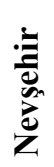 & 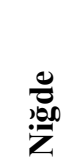 & 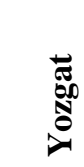 & $\begin{array}{l}\hat{0} \\
\hat{v} \\
\omega\end{array}$ & 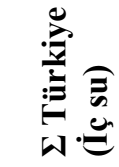 & $d^{2}$ \\
\hline \multirow[t]{3}{*}{ Oncorhynchus mykiss } & 2016 & 900 & 361 & 1098 & & 163 & 230 & 2752 & 99712 & 2,8 \\
\hline & 2017 & 528 & 302 & 848 & & 112 & 806 & 2596 & 101761 & 2,6 \\
\hline & 2018 & 678 & 295 & 1107 & & 67 & 1050 & 3197 & 103192 & 3,1 \\
\hline \multirow[t]{3}{*}{ Cyprinus carpio } & 2016 & & & & 2 & & 29 & 31 & 196 & 15,8 \\
\hline & 2017 & & & & 4 & & 12 & 16 & 233 & 6,9 \\
\hline & 2018 & & & & 4 & & 1 & 5 & 212 & 2,4 \\
\hline \multirow[t]{3}{*}{ Oreochromis sp. } & 2016 & & 58 & & & & & 58 & 58 & 100,0 \\
\hline & 2017 & & 8 & & & & & 8 & 8 & 100,0 \\
\hline & 2018 & & 12 & & & & & 12 & 12 & 100,0 \\
\hline \multirow[t]{3}{*}{ Toplam } & 2016 & 900 & 419 & 1098 & 2 & 163 & 259 & 2841 & 101557 & 2,8 \\
\hline & 2017 & 528 & 310 & 848 & 4 & 112 & 818 & 2620 & 103967 & 2,5 \\
\hline & 2018 & 678 & 307 & 1107 & 4 & 67 & 1051 & 3214 & 105118 & 3,1 \\
\hline
\end{tabular}

\section{Sonuç ve Öneriler}

KOP Bölgesi illerinde en yüksek avcılık değerine sahip olan türlerin tamamı egzotik veya balıklandırma yoluyla taşınmış türlerden oluşmaktadır. Egzotik türlerin bazıları istilacı hale gelerek ekosistemin işleyişini olumsuz şekilde etkilemektedir. Nitekim Beyşehir Gölüne sudak aşılanması bazı endemik türlerin neslinin tükenmesine sebep olmuştur. Yine Beyşehir Gölüne gümüşi havuz balığının aşılanması ile birlikte göldeki doğal türlerin avcılık değerinde büyük düşüşler meydana gelerek baskın tür haline gelmiştir. Benzer şekilde Yozgat ve Kırşehir illerindeki yüksek avcılık değerleri bir diğer egzotik tür olan gümüş balığından kaynaklanmaktadır. Bu durum su kaynaklarımızdaki biyoçeşitliliğin ortaya konarak takip edilmesi gerektiğini ortaya çıkartmaktadır. Çünkü kısa vadede 
avcılık miktarı açısından olumlu bir sonuç ortaya çıkarttığı düşünülebilecek egzotik balıkların uzun vadede ekosistem üzerinde çok büyük olumsuz etkiler ortaya çıkartabileceği açıktır.

Kırşehir ilindeki avcılık miktarının hemen hemen tamamı Hirfanlı Baraj Gölünden sağlanmaktadır. Konya ilindeki avcılığın en yoğun yapıldı̆̆ 1 yer ise Beyşehir Gölüdür. Sürdürülebilir avcılık ilkeleri doğrultusunda balıkçılığın idaresine ilişkin çalışmalar yapılması ve balıkçılığın bilimsel temellere dayalı olarak gerçekleştirilmesine yönelik stratejiler geliştirilmesi gerekmektedir. Bahse konu olan avlak sahalarında faaliyet gösteren avcılık kooperatiflerinin eğitimle desteklenerek üretime katk1 vermeleri sağlanabilir. KOP kapsamında yer alan illerde 2018 yılı itibariyle, toplam Türkiye iç su avcılığının $\% 10,8$ 'i ve yetiştiriciliğinin ise \%3,06'l1k kısmı gerçekleştirilmektedir. Türkiye'nin en büyük tatlı su gölü olan Beyşehir Gölü ve yine Kızılırmak üzerinde kurulu olan barajların bu üretimde önemli bir payı bulunmaktadır.

Türkiye'nin toplam su ürünleri üretimi içerisindeki KOP Bölgesinin payı \%1 düzeyindedir. Ancak KOP Bölgesinde, gökkuşağı alabalığı dışında, elde edilen ürünlerin büyük bir kısmının çok düşük ticari değere sahip gümüş balığı ve gümüşi sazan türlerinden oluştuğu düşünüldüğünde, KOP Bölgesinin ekonomik anlamdaki payının çok daha düşük olduğu görülmektedir.

KOP Bölgesinde gökkuşağ1 alabalığg yetiştiriciliğine dayalı bir üretim söz konusudur. Bu nedenle KOP Bölgesindeki çiftliklerin mevcut durumlarının ortaya konması halinde verimlilik artışına yönelik alınması gereken önlemlerin ortaya konması ve böylece verimlilik artışına bağlı üretim miktarının yükseltilmesi de mümkün olacaktır. Üretim miktarının ve karlılığın arttırılmasında en önemli konulardan bir tanesi de birim zamanda hızlı büyüme/yüksek verimliliğe sahip genetik hatlı bireylerin yetiştirilmesidir. KOP bölgesindeki çiftliklerdeki anaç stoklarının veya yavru temin ettikleri bireylerin genetik yapısının tespit edilerek durum tespiti yapılması gerekmektedir.

Son yıllarda su ürünleri yetiştiricilik sektöründeki büyümenin temel kaynağı kafes balıkçılığıdır. Sistemin taşınabilir olması, çok kısa zamanda kurulabilmesi ve yetiştiricilik açısından avantajlı olması gibi sebepler üreticilerin kafes sistemlerine yönelmesine sebep olmuştur. Hirfanlı Baraj Gölünün Kırşehir Merkez ve Kaman İlçesi sınırları içerisinde kalan büyük bir alanının yetiştiricilik faaliyetine açılması KOP Bölgesini balık yetiştiriciliği açısından çok daha da önemli bir bölge haline getirecektir. Özellikle de Tarım ve Orman Bakanlığı'nın su ürünleri desteklerinde değişikliğe gitmesi ve iç piyasada yerli somon olarak pazarlanan büyük boy gökkuşağı alabalığına daha fazla destek vermesi ile birlikte işletmelerin yetiştiricilik miktarında artış olması beklenmektedir. Büyük boy gökkuşağı alabalığg yetiştiriciliğine geçilmesi ile birlikte bölgede bazı sorunların da ortaya çıkması muhtemeldir. Kilo üzeri alabalık yetiştiriciliği ile birlikte balıkların üreme çağına gelmesi hem balık büyütmede gecikmelere hem de et kalitesinde düşüşe sebep olacaktır. Bu gibi sorunları ortadan kaldırmak için balık yetiştiriciliğinde biyoteknolojik yöntemlerin kullanılması kaçınılmazdır. Bölge balıkçılarının dişi balık yetiştiriciliği konusunda bilgilendirilmesi ve dişi yavru elde etme metotları konusunda gerekli eğitimler verilmesi gerekmektedir. Gerekli olması halinde uygun genetik özelliklere sahip anaç stoklarının temininin sağlanması ve/veya teşvik edilmesi yetiştiricilikte verim ve gelir artış1 sağlayabilecektir.

\section{Kaynaklar}

Anonim. 2019. Su Ürünleri Raporu. Ziraat Mühendisleri Odas1. http://www.zmo.org.tr/genel/bizden_detay.php?k od $=27302 \&$ tipi $=38 \&$ sube $=0$. Yayın Tarihi: 10.02.2017, Güncellenme: 01.02.2018, Erişim: 04.10.2019.

Dikel, S. 2001. Tilapya Türü Olan Oreochromis aureus ve Oreochromis niloticus ile Bunların Melezlerinin Çukurova'da Havuz Koşullarında Yetiştirilmesi ve Büyüme Performansları ile Karkas ve Besin Özelliklerinin Karşılaştırılması. E.U. Journal of Fisheries \& Aquatic Sciences, 18(3-4), 445-457.

Dikel, S. 2006. Tuzlusu Ortamlarında Tilapia Yetiştiriciliği. E.U. Journal of Fisheries \& Aquatic Sciences, 23(1/2), 199-204.

Emiroğlu, M. 1987. Türkiye'nin Su Ürünleri Üretimi. Ankara Üniversitesi Dil ve Tarih-Coğrafya Fakültesi Dergisi, 31(1-2), 77-146.

FAO. 2019. FAO yearbook. Fishery and Aquaculture Statistics 2017/FAO annuaire. Statistiques des pêches et de l'aquaculture 2017/FAO anuario. Estadísticas de pesca y acuicultura 2017. Rome/Roma.

Özdemir, N., Aras, N.M., 2005. Türkiye ve Avrupa Birliği (AB) Su Ürünleri Sektörünün Üretim, Tüketim, İhracat ve İthalat Yönünden Karşılaştırılması. Atatürk Üniversitesi Ziraat Fakültesi Dergisi, 36(1), 109-116.

TUIKK. 2019. Türkiye İstatistik Kurumu. Su ürünleri istatistikleri; Alıntılanma adresi http://www.tuik.gov.tr/PreHaberBultenleri.do?id $=30697,20.12 .2019$. 